\title{
Supply strategy configuration in fragmented production systems: an empirical study
}

\author{
Claudia Chackelson, Ander Errasti, Sandra Martinez, Javier Santos \\ Tecnun - University of Navarra (Spain) \\ cchackelson@,tecnun.es,_aerrasti@,tecnun.es,smartinez@,tecnun.es,jsantos@,tecnun.es
}

\section{Abstract:}

Purpose Companies survive in saturated markets trying to be more productive and more efficient. In this context, it becomes critical for companies to manage the entire supply network to optimize overall performance. Hence, the supply strategy plays an important role because it influences the way in which production and logistics network has to be configured and managed. This paper explores the benefits obtained configuring different supply strategies adapted to customer needs.

Design/methoddogy/approadr For this purpose a case research from a Tier 2 point of view of the supply chain has been conducted.

Findings: The case research demonstrates that a higher service level, less holding costs and increase turnovers can be obtained implementing the adequate supply strategy.

Originality/value There is a scarcity of research specifically focused on applied Supply Chain Principles within network configuration processes. Moreover, there are few empirical studies of global Tier 2 with multiple decoupling points into its supply chain network.

Keywords: supply chain management, supply strategy, Tier 2, case study 


\section{Introduction}

In the twenty-first century landscape, firms must compete in a complex and challenging context that is being transformed by many factors, from globalization, technology development, and increasingly rapid diffusion of new technology, to the development and use of knowledge (Jackson, Hitt \& Denisi, 2003). The need to accomplish international markets development with sophisticated and diverse customer requirements and at the same time put into practice global purchasing strategies exploiting worldwide supplier market opportunities are influencing the way production and logistics networks have to be configured and managed.

Moreover, nowadays the fragmentation of the productive processes and multi-location of the activities have acquired relevancy. This implies that agents integrating the global supply chain (i.e. distributors, original equipment manufacturers, manufacturers, suppliers and logistic operators, etc.) have to carry out new operations and supply strategies over the national borders to reach optimal levels of quality, flexibility and cost. It affects in the design of the productive and logistic system, as well as the associated supplier network design.

The production and logistic system strategy or Operations Strategy has to be aligned with the Business product/market Strategy (Monczka, Handfield, Guinipero \& Patterson, 2009). In this context, the production and logistic system strategy conditions the decisions and reengineering projects to be carried out in a company in the medium and short term to improve the competitive advantage of the supply chain. Operations strategy has to gain more effectiveness and efficiency over operations resources through defining and implementing suitable supply strategy decisions, managing the tangible resources, and developing operations capabilities in order to reach the performance objectives of the market requirements.

This paper presents an empirical study developed in a global Tier 2 with multiple O.E.M requirements. Firstly, in the literature review the supply chain management, supply strategies and supply chain agents' classification are exposed, as well as the research question. Secondly, the researchers describe the case study and finally the conclusions are stated.

\section{Literature Review}

The APICS Dictionary (Blackstone \& Cox, 2004) describes the supply chain as the processes from the initial raw materials to the ultimate consumption of the finished product, via different agents (suppliers, manufacturing plants, warehouses, customers, etc.). Supply Chain Management coordinates and integrates all activities of planning, sourcing, manufacturing and delivery. Over the past few decades, supply chain integration efforts have been fostered by tools and concepts which, while the names have changed, are all designed to reduce variance and waste within the organization as well as the inter-organizational network (Birou, Germain \& Christensen, 2011). Stevens (1989) proposed a model to integrate the material flow. The model proposes that companies should integrate internally their logistics activities with the 
activities of other functional units, such as Purchasing, Production and Distribution. Once this internal integration is achieved, it is extended to other supply chain members, such as customers and suppliers. The external integration among organizations aims to achieve competitive enterprises, because competition in the future will be between global supply chains, and no longer between single companies as has been the case (Christopher \& Towill, 2001; Cox, 1999). Nevertheless, it needs changing traditional organizational structures and attitude among organizations (Alpander \& Carroll, 1995).

In relation to the company's position in the supply chain, supply chain vertical disintegration generates the existence of multiple agents whose value proposition to customers is different. The number of supplier companies and the value added in each link in the supply chain is different. In the literature, under the supply chain approach, the following agents could be differentiated:

- (Original equipment manufacturer): It is the leading manufacturer of a product, good o service and which usually leads the short and long wave of the value chain, especially from the demand generation, design and product development to the total manufacture.

- Tier 1 (Systems integrators suppliers): It is a systems or modules supplier's which usually requires a system product engineering and the integration of a second and third tier network supplier (Tier 2 and Tier 3 ) both not only for its development but also for its manufacture and supply.

- Tier 2 (Value added component suppliers): It is a component or raw materials supplier whose supply requires an input partial in the product engineering and higher in the engineering process to fulfill the customer requirements.

- Tier 3 (Raw materials and non critical component suppliers): It is the raw materials and components supplier whose specification is standard or is closed by the client.

Facilities are critical nodes of a global manufacturing network from the supply chain system perspective. Therefore, to implement the most efficient principles such as demand driven supply chain (Christopher \& Towill, 2001), the design of facilities should consider the integration of the Logistic Chain oriented to increase customer satisfaction, reduce total cost and increase return of capitals (see Figure 1).

The flow systems in a facility is the flow of materials into the manufacturing plant dock to dock, but also the flow of information and logistic functions which conditions these activities. In order to apply the supply chain principles, it is necessary to integrate the logistic functions such as demand planning, service planning, production planning and scheduling, and procurement planning. 


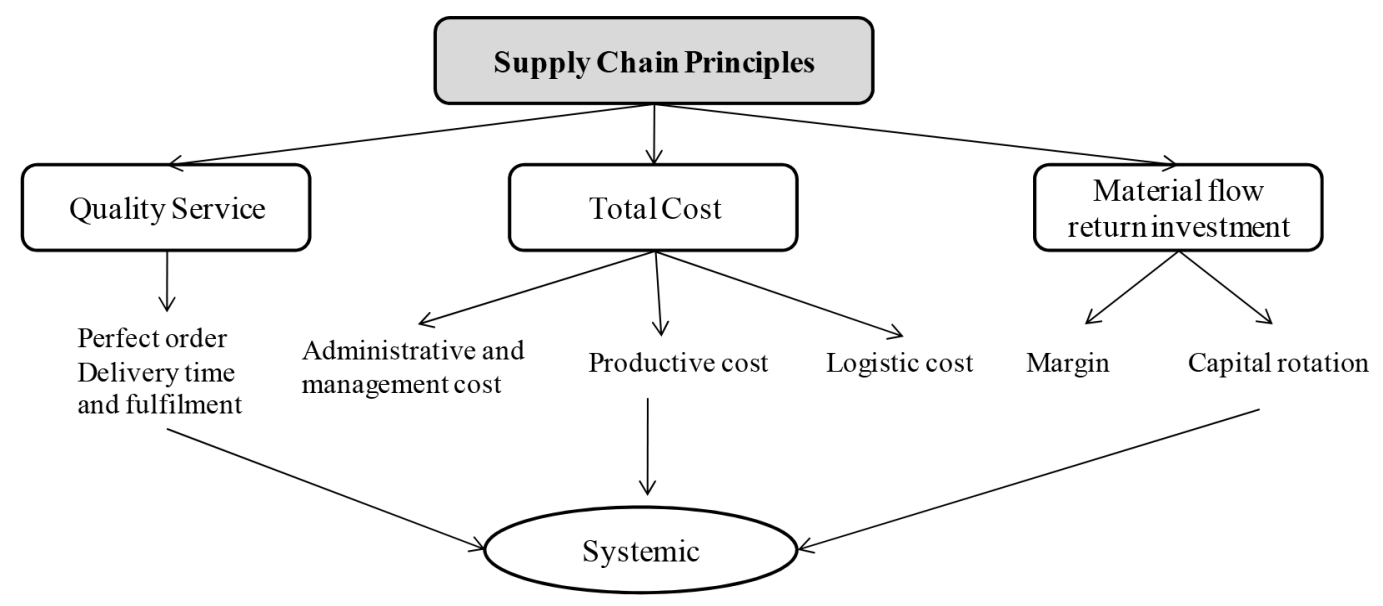

Figure 1. Supply chain principles (Errasti, 2006)

Nevertheless, in a multisite and fragmented production system, where the supplier network is composed of local or domestic suppliers and offshore suppliers and manufacturing facilities, these offshore suppliers and facilities need the coordination of the supply network with different delivery times and procurement reliability. The gap between customer delivery time and supply chain lead time needs forecast driven manufacturing, supplying and purchasing decisions.

The lead time gap between the production lead time, i.e., how long it takes to plan, source, manufacture and deliver a product $(P)$, and the delivery time, i.e., how long customers are willing to wait for the order to be completed (D), is key element of the supply chain (Simchi-Levi, Kaminsky \& Simchi-Levi, 2000). Comparing P and D, a company has several basic strategic order fulfilment options: Engineer to Order (ETO) - (D >>P), Make to Order (MTO) - $(D>P)$, Assemble to Order (ATO) - $(D<P)$ and Make to Stock (MTS) or Build to Forecast (BTF) - $(D=0)$ (Wikner \& Rudberg, 2005). Even though there are several supply strategies, this research is focused on MTO and MTS.

Given the inherent differences in these manufacturing strategies; MTO firms are characterized by low volume, customization, process flexibility, higher work-in-process inventory, lower finished goods inventories, and longer lead-times; and MTS firms are characterized by high volume, standardization, dedicated equipment, lower work-in process and higher finished goods inventories, and shorter lead-times (Birou et al.,2011).

Nevertheless, the implementation of the right supply strategy in global and fragmented production systems becomes more difficult because there is a need of settling down more than a decoupling point. Multiple Decoupling Points and the Order Penetration Point (OPP) have to be fixed to assure the supply strategy. The OPP divides the manufacturing stages that are forecast-driven (upstream of the OPP) from those that are customer-order-driven (the OPP and downstream). The OPP is defined as the point in the manufacturing Value Chain where a product is linked to a specific customer order. Sometimes the OPP is called the Customer Order Decoupling Point (CODP) to highlight the involvement of a customer order. Nevertheless, it is 
not the same because in a fragmented international material flow there could be various CODPs, but there is only one OPP. Thereby, the OPP is one of the strategic decisions because of its impact on the supply chain performance in terms of service and cost.

In spite of the importance of considering the Supply Chain Principles oriented to increase customer satisfaction, reduce total cost and increase return of capitals, there is a scarcity of research specifically focused on applied them within the configuration and implementation of the supply chain. Moreover, there are also few empirical studies about a global Tier 2 which has got multiple decoupling points in its supply chain network. Hence, this gives rise to the following research question:

- How could the Supply Chain Principles be applied in a global Tier 2 company with multiple O.E.M.s requirements?

\section{Case study}

A Case study approach is selected because it has been pointed as a useful tool for theory building as well as for exploratory, descriptive or explanatory research (Rowley, 2002). Moreover, Miles and Huberman (1994) stated that a typical or representative single case is an instance that have grate payoff in case research. When the goal is to capture the conditions of a commonplace situation, a single-case design is appropriate (Yin, 2009). The lessons learned from these cases are assumed to give information about experiences at the average institution. Thus, a single case can confirm, challenge, or extend the theory.

The selected company is an Electronic Manufacturer that has located three production plants in America, Asia, and Europe respectively to meet the demand of global market. It could be classified as a Tier 2 that serves several O.E.M.s of diverse sectors: equipment goods, household appliances, automotive, and wind sector, among others. This international strategy and the heterogeneity of its clients make the selected company the ideal place to perform the single-case study and answer the research question previously formulated

The researchers have been actively involved analysing the Logistic Functions (demand planning, service planning, order management, production planning and scheduling, and procurement planning) to achieve better service, cost or turnover performance. The two main supply strategies are: (1) MTS, delivery to customer from finished products and a CODP of raw materials and parts; (2) MTO, deliver to order with CODP of raw materials and parts.

Both finish products management and raw materials management were improved by applying the Integral Logistic Chain Principles and integrating the Logistic Functions (stock and raw materials planning, demand planning, and production planning and scheduling) (see Figure 2).

The analysis has been done by-client taking into account the singular characteristics of each O.E.M., but also having in mind the big picture in order to avoid subsystem improvements that 
negatively affect the performance of the entire system. The methodology followed during this project will be illustrated with one of the Tier 2 clients, an Equipment goods O.E.M., from now on called Client $\mathrm{X}$.

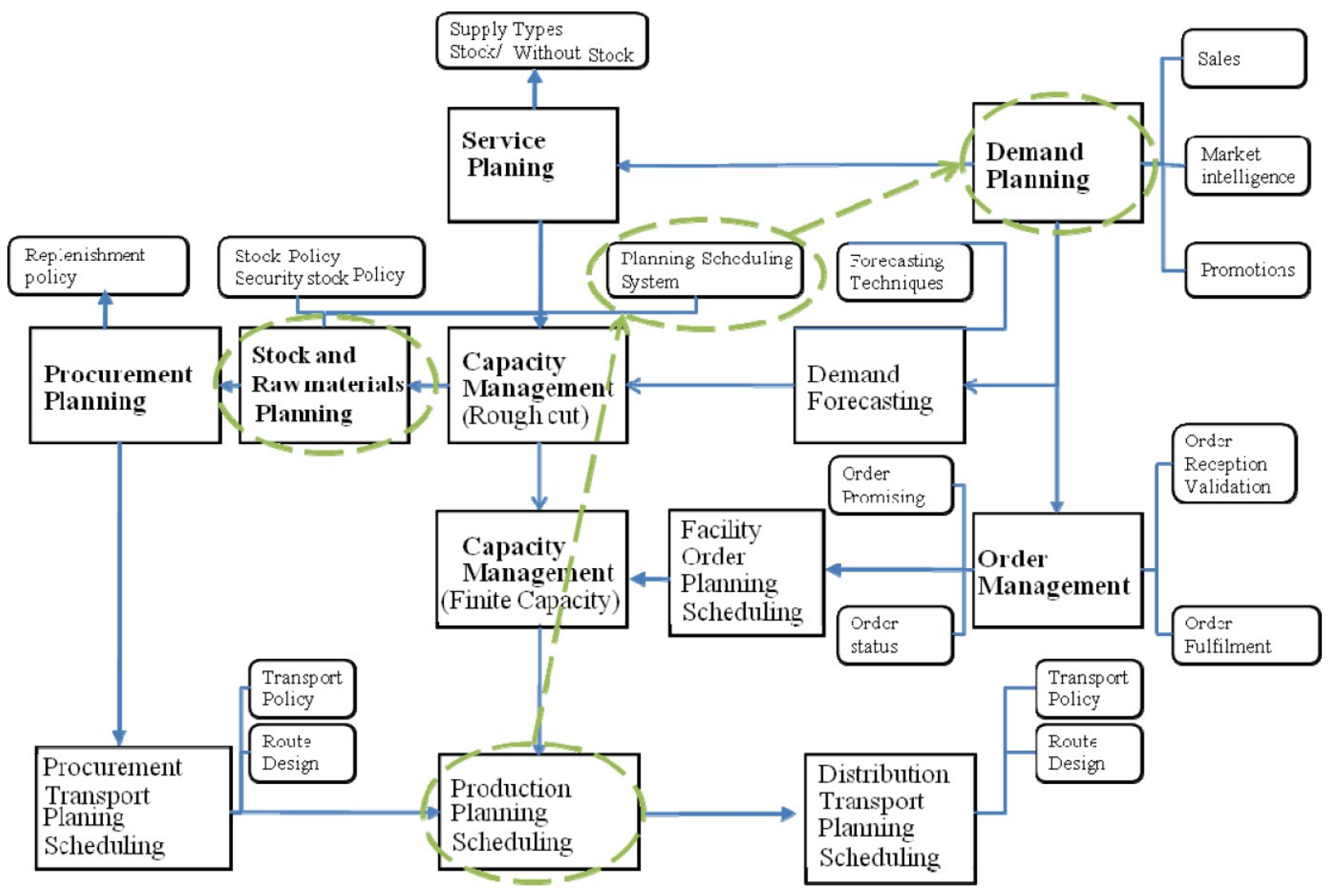

Figure 2. Logistic functions (Errasti, 2011)

\subsection{Alternatives and opportunities for the O.P.P}

Firstly, the researchers analysed the O.P.P with the aim of improving the finish product. The company manufactures and delivers more than 60 finished products for Client $X$ according to MTS supply strategy. All of them have been clustered according to both a value $A B C$ analysis and a volume $A B C$ analysis. The main objective of this classification is to select the most suitable production/supply strategy for each product, incrementing stock turnovers and avoiding overstock (reducing the risk of obsolescence). Moreover, in order to carry out a more precise analysis, both $A B C$ categorisations were subdivided generating five subclassifications: AAA (20\%), AA (20\%), A (40\%), B (15\%), and C (5\%).

As a result, different production/supply strategies and production planning and scheduling alternatives were suggested for each one of the expose classifications, achieving great results. 


\begin{tabular}{|l|l|l|}
\hline Product category & \multicolumn{1}{|c|}{$\begin{array}{c}\text { Suggested supply strategies or } \\
\text { planning/scheduling alternatives }\end{array}$} & \multicolumn{1}{|c|}{ Benefits } \\
\hline $\begin{array}{l}\text { Strategic Items: extreme volume } \\
\text { (AAA, AA, and A) expensive (AAA, } \\
\text { AA, A, and B) }\end{array}$ & Production batch reduction ${ }^{1}$ & $\begin{array}{l}\text { Avoiding excessive holding costs and } \\
\text { keeping high service level }\end{array}$ \\
\hline Medium volume (B) & $\begin{array}{l}\text { Joint and finished products grouping } \\
\text { batch strategy }\end{array}$ & $\begin{array}{l}\text { Keeping efficiency and keeping high } \\
\text { service level }\end{array}$ \\
\hline Low volume (C) Low price (C) & $\begin{array}{l}\text { (a) Production batch reduction } \\
\text { (b) Adopting a MTO strategy }{ }^{2} \text { with a } \\
\text { CODP of raw materials }\end{array}$ & $\begin{array}{l}\text { Avoiding excessive holding costs and } \\
\text { keeping high service level }\end{array}$ \\
\hline
\end{tabular}

${ }^{1}$ This decision must not be made isolated, but considering the respective increment of production costs. Therefore, a production batch reduction was finally implemented for those products that holding cost reduction significantly compensates production cost increment.

${ }^{2}$ Adopting a MTO strategy with a CODP of raw materials is the preferred option, but its implementation implies greater reliance on suppliers lead time than the fist alternative. In a multisite and fragmented international production system longer lead times and lack of reliability are common scenarios. In each case, supplier reliability was taking into account for making this decision.

Table 1. Strategies and benefits for each finish product category

\subsection{Alternatives and opportunities for the C.O.D.P}

Secondly, the researchers analysed the C.O.D.P with the aim of improving raw materials management. The Client $X$ production process requires more than 800 raw material items procurement; all of them were managed with a CODP with stock and a replenishment systems based on forecast demand due to the long delivery times. These items were classified according to family grouping strategy. There were 79 different families, which only 5 of them represented $75 \%$ of total purchase. These 5 families were considered strategic, consequently they were analysed in greater detail. Four important levers were recommended for these strategic items. For the rest of the families two alternatives were suggested according to its volume and price.

\begin{tabular}{|c|c|c|}
\hline Product category & $\begin{array}{c}\text { Suggested supply strategies or planning/scheduling } \\
\text { alternatives }\end{array}$ & Benefits \\
\hline Strategic Items & $\begin{array}{l}\text { (a) The stock is storage at the company but it } \\
\text { belongs to the supplier. } \\
\text { (b) The stock is storage at the supplier. } \\
\text { (c) Reducing MOQ (Minimum Order Quantity) } \\
\text { (d) Supply order adjusted to a multiple of the } \\
\text { packaging unit }{ }^{1}\end{array}$ & $\begin{array}{l}\text { Increasing turnovers and } \\
\text { keeping high service level }\end{array}$ \\
\hline Medium volume / Medium price & $\begin{array}{l}\text { Keeping current replenishment strategy based on } \\
\text { forecast }\end{array}$ & $\begin{array}{l}\text { Keeping efficiency and } \\
\text { high service level }\end{array}$ \\
\hline Low volume / Low price & Adopting a stock policy based on position stock level & $\begin{array}{l}\text { Increasing efficiency and } \\
\text { keeping high service level }\end{array}$ \\
\hline
\end{tabular}

${ }^{1}$ This strategy has been implemented if the MOQ could not be reduced

Table 2. Strategies and benefits for each raw material category

\section{Conclusions}

This case study has demonstrated that the integration of Logistic functions helps to achieve higher service level, reduce holding cost and increase turnovers. The most outstanding results are: 
- Finish product management:

- Excessive holding cost in strategic items could be avoided by reducing production batches.

- In order to keep efficiency and high service level, a joint an a finished product grouping batch strategy is recommended for medium volume items.

- Excessive holding cost in low volume and low price products could be avoided by adopting a MTO supply strategy. If this strategy cannot be implemented due to lack of supplier reliability, reducing production batches might be appropriated.

- Raw material management:

- Strategic items turnovers may be increased by adopting one of the following strategies: supplier stock kept at the company, supplier stock kept at the supplier, MOQ reduction or supply order adjusted to a multiple of the packaging unit.

- In order to keep efficiency and high service level, a replenishment strategy based on customer forecast demand is suitable for medium volume and price items.

- Efficiency of low volume and price articles could be increased by adopting a stock policy based on position stock level.

\section{Acknowledgments}

This work has been partially funded by Ministerio de Ciencia e Innovación (DPI2011-26653).

\section{References}

Alpander, G., \& Carroll, L. (1995). Culture, Strategy and Teamwork. The keys to organizational change. Journal of Management Development, 14(8), 4-18. http://dx.doi.org/10.1108/02621719510097389

Birou, L., Germain, R.N., \& Christensen, W.J. (2011). Applied logistics knowledge impact on financial performance. International Journal of Operations \& Production Management, 31(8), 816-834. http://dx.doi.org/10.1108/01443571111153058

Blackstone, J., \& Cox, F. (2004). Creating and managing value in collaborative network. International Journal of Physical Distribution and Logistics Management, 34(3/4), 251-268. http://dx.doi.org/10.1108/09600030410533574

Christopher, M. \& Towill, D. (2001). An integrated model for the design of agile supply chains. International Journal of Physical Distribution and Logistics Management, 31(4), 235-246. http://dx.doi.org/10.1108/09600030110394914 
Cox, A. (1999). Power, value and supply chain management. Supply Chain Management: an International Journal, 4(4), 167-175. http://dx.doi.org/10.1108/13598549910284480

Errasti, A. (2011). International Manufacturing Networks: Global Operations Design and Management. San Sebastian, Spain: Servicio Central de Publicaciones del Gobierno Vasco.

Errasti, A. (2006). KATAIA: Modelo para el análisis y despliegue de la estrategia logística y productiva. San Sebastian, Spain: Doctorado Tecnun.

Jackson, S.E., Hitt, M.A. \& Denisi, A.S. (2003). Managing Knowledge for Sustained Competitive Advantage. San Francisco: Jossey-Bass.

Miles, H., \& Huberman, M. (1994). Qualitative data analysis: a sourcebook. Beverly Hills: CA. Saga Publications.

Monczka, R.M., Handfield, R.B., Guinipero, L.C., \& Patterson, J.L. (2009). Purchasing and Supply Chain Management. 4th Edition. USA: South-Western Cengage Learning.

Rowley, J. (2002). Using case studies in research. Management Research News, 25(1). http://dx.doi.org/10.1108/01409170210782990

Simchi-Levi, D., Kaminsky, P., \& Simchi-Levi, E. (2000). Designing and Managing the Supply Chain: Concepts, Strategies, and Cases. USA: Mac Graw Hill.

Stevens, G.C. (1989). Integrating the Supply Chain. International Journal of Physical Distribution and Materials Management, 19(8), 3-8. http://dx.doi.org/10.1108/EUM0000000000329

Wikner, J., \& Rudberg, M. (2005). Integrating production and engineering perspectives on the customer order decoupling point. International journal of Operations and Production Management, 25(7), 623-641. http://dx.doi.org/10.1108/01443570510605072

Yin, R.K. (2009). Case Study Research: Design and methods. 4th Edition. London: SAGE Publications, Inc.

Journal of Industrial Engineering and Management, 2013 (www.jiem.org)

Article's contents are provided on a Attribution-Non Commercial 3.0 Creative commons license. Readers are allowed to copy, distribute and communicate article's contents, provided the author's and Journal of Industrial Engineering and Management's names are included. It must not be used for commercial purposes. To see the complete license contents, please visit http://creativecommons.org/licenses/by-nc/3.0/. 